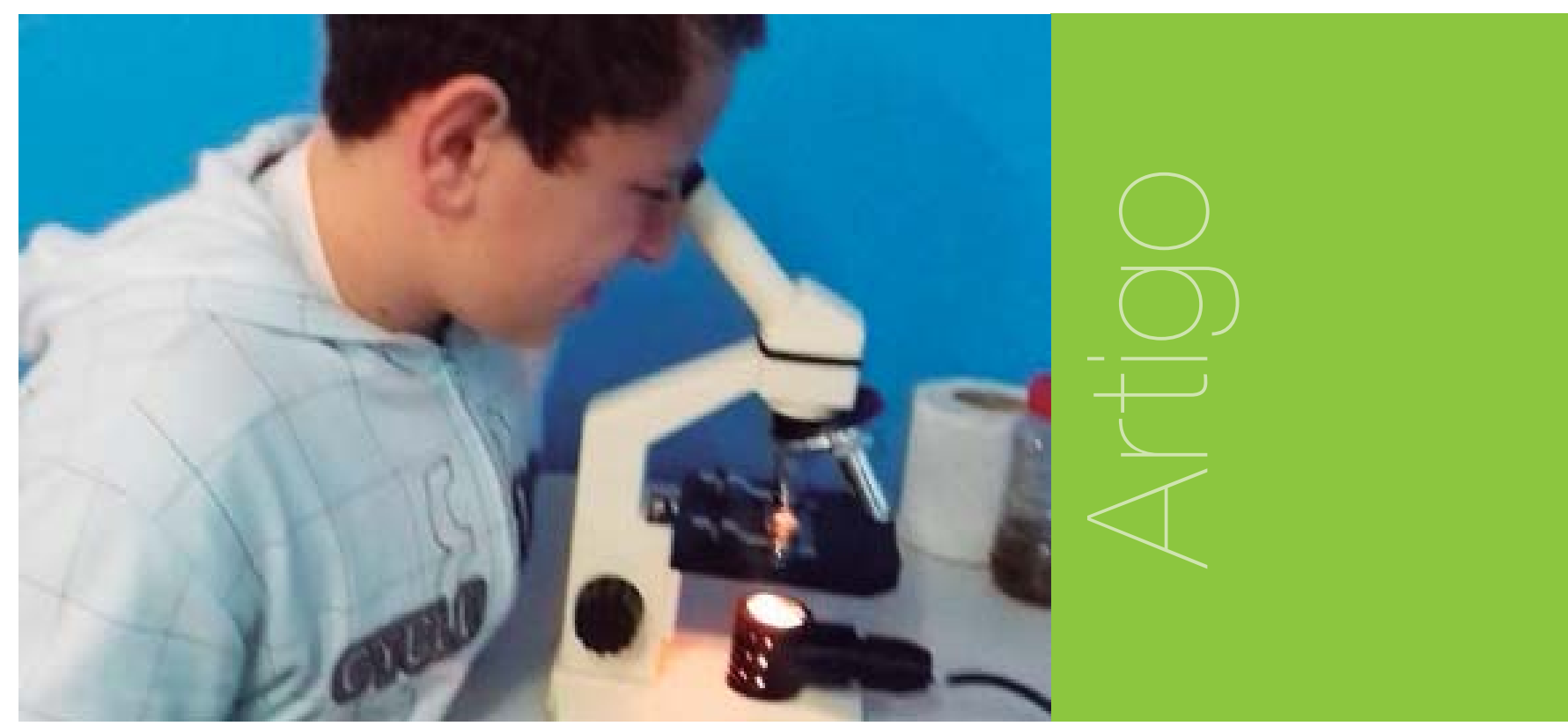

\title{
Estratégias facilitadoras no processo de ensino/ aprendizagem: uma análise no ensino de ciências
}

\section{Giselen Lefer Padilha Renner ${ }^{1}$ - glefer.p@gmail.com}

\section{RESUMO}

Este texto tem como propósito analisar a prática docente, avaliada durante o estágio de observação, à luz de uma epistemologia construtivista e de teorias de aprendizagem. 0 principal objetivo é evidenciar as práticas pedagógicas definidas pela professora de ciências do ensino fundamental de uma escola pública e analisar se as estratégias utilizadas podem facilitar uma aprendizagem de forma significativa, de acordo com a teoria de aprendizagem significativa (TAS), através da observação em sala de aula. Entre os resultados obtidos, destaca-se a observação de vários instrumentos utilizados nas abordagens pedagógicas, um fato que se opõe às metodologias tradicionais de ensino.

\section{PALAVRAS-CHAVE}

Ensino de Ciências. Estratégias de Ensino/Aprendizagem. Estágio de Observação.

\section{ABSTRACT}

The aim of this paper is to analyze teaching practices through observation in the light of constructivist approaches and learning theories. The main objective is to reveal the pedagogical practices defined by the high-school science teacher in a public school, and analyze if the strategies she used can promote meaningful learning, according to the meaningful learning theory (MLT), through observation in the classroom. Some of the present results indicate the use of various tools with pedagogical approaches, a fact that is opposed to traditional methods of teaching.

1 Acadêmica do curso de Licenciatura em Ciências da Natureza com Habilitação em Física, no Instituto Federal de Santa CatarinaIFSC, Câmpus Jaraguá do sul. 


\section{KEYWORDS}

Science Teaching. Teaching / Learning Strategies. Observation.

\section{Introdução}

Este artigo compreende as atividades desenvolvidas no decorrer da unidade curricular Estágio de Observação I (ESO I), do curso de Licenciatura em Ciências da Natureza com Habilitação em Física, do Instituto Federal de Ciência e Tecnologia de Santa Catarina (IFSC) no Câmpus Jaraguá do Sul, Centro.

Em relação ao ensino de ciências, a Lei de Diretrizes e Bases (BRASIL, 1996) ressalta a importância dos conhecimentos adquiridos, visto que prepara os alunos para melhor compreender o mundo e suas transformações por meio da Ciência e Tecnologia.

Os Parâmetros Curriculares Nacionais (PCNs) reforçam a relevância do ensino de ciências nas primeiras séries da escolarização básica, pois é nesse período que a criança aperfeiçoa, constrói e reconstrói seu conhecimento e aprende de forma significativa, através da assimilação e compreensão dos conteúdos apresentados (BRASIL, 1997). Isso pode ocorrer de diversas formas, como, por exemplo, na apresentação dos conteúdos de diferentes maneiras.

Nesta perspectiva, para que o sujeito possa adquirir significados e interpretar o mundo em que vive, tendo criticidade para atuar nele, é imprescindível que se tenha o cuidado em promover estratégias de ensino que possibilitem tal reflexão e ação.

Com relação às estratégicas didáticas, é substancial que no ensino de ciências haja uma busca por novas práticas, que facilitem o aprendizado dessa disciplina, que muitas vezes é abstrata e possui conteúdos diversificados. Essas práticas devem ter como objetivo estimular e provocar no aluno 0 interesse pela procura de respostas que expliquem tais condições.

Uma vez estabelecida a relação entre 0 ensino de ciências e as estratégias utilizadas, este artigo tem a proposta de analisar de forma crítica e substancial, e não apenas a crítica pela crítica, fornecendo uma visão de que o ensino pode ser ao mesmo tempo significativo e prazeroso ao aluno e ao professor.

Diante deste contexto, é possível realizar a análise das estratégias pedagógicas utilizadas no ensino de ciências, avaliar se estas proporcionam uma aula mais dinâmica e de que forma ocorre a participação dos alunos, dentro de uma perspectiva de aprendizagem significativa. Este se constitui o objetivo deste trabalho.

\section{Metodologia}

A técnica utilizada para a pesquisa foi a de observação, que desempenha papel imprescindível para obtenção de material resultante e análise dos dados. As observações se deram de forma sistemática, com registros de comportamentos, através de uma linguagem clara, objetiva e concisa.

A observação é sempre utilizada na etapa de coleta de dados e pode ser conjugada a outras técnicas ou utilizada de forma exclusiva.

\footnotetext{
Por ser utilizada, exclusivamente, para a obtenção de dados em muitas pesquisas, e por estar presente também em outros momentos da pesquisa, a observação chega mesmo a ser considerada como método de investigação. [...] e os fatos são percebidos diretamente, sem qualquer intermediação. Desse modo, a subjetividade, que permeia todo o processo de investigação social, tende a ser reduzida (GIL, 2008, p. 119).
}

As observações se deram na disciplina de Ciências no ensino fundamental de uma escola pública, cumprindo um total de 24 horas-aula observadas nos anos do ensino fundamental, e 16 horas de observação da instituição escolar em que foram realizadas, durante o período entre março e maio de 2016. 
A instituição foi selecionada utilizando um critério de proximidade da pesquisadora, e as turmas foram selecionadas com o critério de amostragem aleatória simples, abrangendo pelo menos uma turma de cada ano do ensino fundamental.

Após a observação das estratégias didáticas utilizadas no ensino de ciências de uma escola de ensino fundamental, os dados obtidos foram analisados sob uma perspectiva de aprendizagem significativa, ou seja, avaliando qual o potencial de cada ação realizada em relação ao processo de ensino/aprendizagem.

Para Moreira (2012), a aprendizagem significativa ocorre segundo duas condições essenciais: 1) o material de aprendizagem deve ser potencialmente significativo e 2) o aprendiz deve apresentar uma predisposiçã̃o para aprender. A primeira implica em que o material de aprendizagem (livros, aulas, aplicativos etc.) tenha significado lógico, relacionável de maneira não arbitrária e não literal a uma estrutura cognitiva apropriada e relevante. Também implica que 0 aprendiz tenha em sua estrutura subsunçores pertinentes, com os quais o material possa ser relacionado. Em síntese: 0 material deve ser relacionável à estrutura cognitiva do aluno e este deve ter o conhecimento prévio necessário para relacionar o conhecimento novo de forma não arbitrária e não literal.

\section{Resultados e Discussão}

Este texto teve como princípio norteador o estudo da didática das aulas, e não análise de metodologias. Tanto a didática como a metodologia estudam os métodos de ensino, no entanto, a metodologia estuda os métodos de ensino realizando a classificação, sem juízo de valor. A didática faz um julgamento ou uma crítica de valor sobre os métodos de ensino. "Podemos dizer que a metodologia nos dá juízos de realidade, e a didática nos dá juízo de valor" (HAIDT, 1999, p.43).

As estratégias didáticas possuem várias definições, porém todas convergem em um ponto no qual podem ser meios que facilitem o processo de aprendizagem. Segundo Haidt: "As estratégias didáticas ou procedimentos de ensino se destacam como uma forma de intervenção que contribui para o professor colocar o aluno em contato com fatos, ou fenômenos que thes possibilitem mudar sua conduta" (HAIDT, 1999, p.35).

A análise inicial revelou que a professora se utiliza de vários instrumentos pedagógicos, e visto que ainda se observa no cenário atual da educação a presença de metodologias tradicionais de ensino nas quais o conteúdo é apresentado ao aluno apenas no quadro e com a narrativa na qual somente o professor relata a matéria, se caracterizando como diferencial.

0 primeiro instrumento utilizado na abordagem pedagógica dentro da sala de aula foi 0 livro didático, disponibilizado pelo PNLD (Plano Nacional do Livro Didático), oferecido para as escolas públicas. 0 uso do livro pode facilitar o trabalho do professor, e também a aprendizagem, uma vez que fica integralmente com 0 aluno, podendo ser consultado a qualquer momento em casa. Este, porém, não deve ser a única ferramenta utilizada, pois restringe os conteúdos, podendo ser considerado, então, como um orientador dos trabalhos.

0 livro didático é um instrumento muito importante no processo de ensino. É uma maneira mais acessível de adquirir os conteúdos e em muitos aspectos facilita 0 acompanhamento do mesmo. Por outro lado, pode tornar-se vicioso em sala de aula, o que acaba prejudicando no aprendizado do aluno, pois muitos apresentam conteúdos fragmentados, sem relação conteúdo/conceitos. Muitas vezes não existem questionamentos que instiguem 0 aluno a raciocinar sobre 0 que está sendo discutido (FRISON et al., 2009, p. 5).

Este fato foi percebido durante a observação das aulas de ciências, ou seja, o livro utilizado como norteador dos trabalhos em sala de aula, porém não como única ferramenta. 0 conteúdo do livro é bem detalhado pela professora e as imagens bastante exploradas, o que facilita 0 entendimento do texto. Em alguns casos, a professora considera o conteúdo do livro incompleto e busca informação em outros meios. Esta visão de que o livro pode apresentar defasagem de conteúdo, representa que a mesma possui interesse na qualidade do ensino que oferece aos seus alunos, e conhecimento sobre os temas apresentados. 
Alguns questionamentos são realizados pela professora antes da apresentação do conteúdo, não propriamente elaboração de hipóteses, mas como uma análise prévia dos conhecimentos que os alunos possuem acerca do tema. Na teoria da aprendizagem significativa, os conhecimentos prévios dos alunos são 0 eixo central da pedagogia de ensino. Ausubel destaca a importância dos conhecimentos prévios na aquisição de novos conhecimentos, através dos subsunçores (MOREIRA, 1999). É a variável que mais influencia na aprendizagem e a partir dela que as atividades deverão ser orientadas. Seria 0 primeiro passo de uma pedagogia investigativa e a elaboração de hipóteses, a segunda. Porém, a didática utilizada pela professora não se caracteriza como investigativa, o que poderia ser considerada como um complemento no processo de ensino/ aprendizagem. As aulas com caráter investigativo instigam 0 aluno a propor soluções para um problema e proporcionam a auto avaliação, pois têm a possibilidade de testar suas propostas iniciais, seus conhecimentos prévios.

Os conteúdos são apresentados como um segmento linear, do mais simples para o mais complexo, o que pode ser considerado como um processo favorável à aquisição do real conhecimento sobre os temas. Para Brunner (MOREIRA, 1999), a estrutura com que os conteúdos são apresentados é fundamental no processo de aprendizagem, e 0 ideal é que seja apresentado do mais simples para o mais complexo (currículo em espiral).

0 livro didático, como mencionado, atua como norteador das atividades e as propostas estratégicas são diferentes nas etapas de ensino.

Há nas turmas de $6^{\circ}$ ano a elaboração de seminários em grupo com a confecção de cartazes relacionados a um conteúdo já visto pela turma. Esta atividade pode contribuir para que 0 aluno organize 0 que aprendeu em sala, mostrando sua visão sobre os conteúdos, bem como criar habilidades de síntese ou resumo, além de promover a interação social. Quanto à interação entre os sujeitos, Vygotski afirma que: "[...] ao interagir, é a subjetividade construída socialmente que se manifesta, modificando ativamente a situação estimuladora como uma parte do processo de resposta a ela" (VYGOTSKI, 1991, p. 15). Nesta perspectiva, pode-se afirmar que além de assimilar os conceitos envolvidos, o aluno se desenvolve como ser individual, promovendo a construção de sua identidade. Além disso, Vygotski afirma que através dos signos, que são símbolos, o indivíduo produz significados e as representações dos cartazes produzidos podem se constituir como signos, nos quais os conteúdos ganham significado para os alunos, promovendo uma aprendizagem significativa.

Nas turmas do $7^{\circ}$ ano são realizadas muitas experimentações e no momento do estágio ocorreu uma "cultura de bactérias", visivel na Figura 1.

Fonte: Autoria própria.

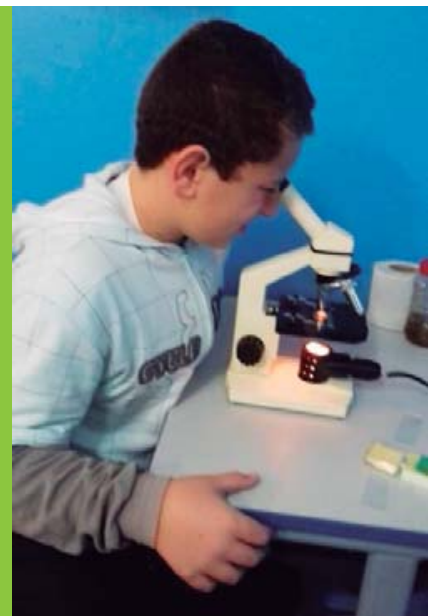

Nesta atividade, os materiais individuais são de responsabilidade dos alunos e os equipamentos utilizados, nesse caso o microscópio, é levado pela professora, pois a escola não dispõe de tal recurso. Os alunos acompanham o desenvolvimento das bactérias, anotam e desenham o que observam. Esta prática de experimentação foi um momento em que os alunos tiveram muita atenção ao que ocorria. Este instante seria ideal para conduzir uma maior participação dos 
alunos acerca dos procedimentos e materiais utilizados, tentando fazer com que eles mesmos buscassem as respostas, construindo o conhecimento a partir de suas concepções.

Questionamentos como o porquê de preparar um caldo para depois inserir bactérias presentes no meio, e o que deve conter neste caldo, para que os seres microscópicos pudessem se desenvolver, poderiam ser algumas questões.

Ainda nessas turmas, no final de cada conteúdo, os alunos têm a função de elaborar um desenho em um caderno, explanando os conceitos que foram trabalhados. Neste caderno de desenhos, de uso exclusivo para a disciplina de ciências, é interessante avaliar como os alunos organizam o pensamento, enquanto desenham e resumem o que aprenderam.

Alguns alunos fizeram mapas conceituais, o que colabora para que novas ligações entre conceitos já existentes sejam feitas e aumenta a possibilidade de uma aprendizagem significativa. É o caso em que o significado é adquirido por interação com um determinado subsunçor (conhecimento prévio já existente na estrutura cognitiva), que o sujeito já tem em determinado campo de conhecimentos (AUSUBEL, 2003).

Ainda neste caderno, pode-se perceber a concepção de alguns alunos acerca da imagem que eles têm de um cientista. Em alguns cadernos, foi possível verificar que os alunos possuem uma visão desmitificada, pois a concepção da maioria das pessoas é de que os cientistas são estereótipos, com cabelos arrepiados, de jaleco, óculos e associados à loucura, e quase sempre são considerados como pessoas especiais, seletos de um grupo no qual não podem ser incluídas pessoas "normais". Isto pode ser verificado na figura 2, com a concepção de uma aluna de que ela pode vir a ser uma cientista.

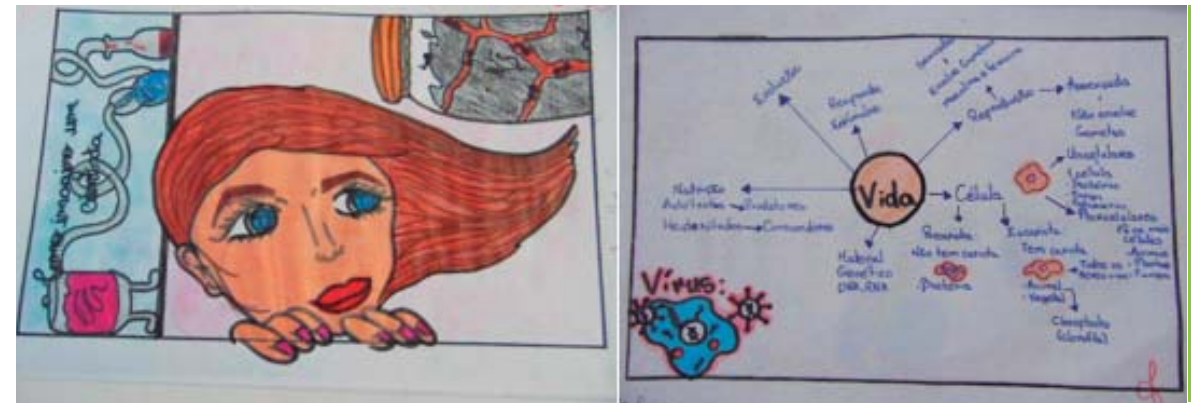

Este recurso, do uso de caderno de desenhos, é bastante utilizado nos anos iniciais da educação infantil, pois provoca a interação do aluno com os temas estudados em sala, além de favorecer as habilidades artísticas e motoras, porém 0 que normalmente acontece é que os professores deixam de utilizar este recurso no decorrer do tempo. Neste período de vida, mais ou menos aos 11 anos, 0 aluno é capaz de traduzir ações em pensamentos e pensamentos em ações. Piaget afirma que nessa fase (estádio da inteligência operatória concreta, de 7-8 a 11-12 anos) a atividade cognitiva da criança torna-se operatória, passando por uma transição entre a ação e as estruturas lógicas mais gerais, com a capacidade de representação de uma ação no sentido inverso de uma anterior, anulando a transformação observada (CAVICCHIA, 2010). Portanto, nessa fase, 0 aluno já pode estabelecer relações de pensamento e ação entre os objetos, e essa atividade tem grande potencial de promover a aprendizagem de forma significativa. Também nessas turmas, foi sugerido que, uma vez por mês, os alunos que tinham interesse, levassem para a aula um experimento construído por eles, sobre qualquer assunto, e explicassem aos demais como e por que funcionava. Essa atividade promoveu um grande interesse nos alunos, tanto aos que querem demonstrar seus projetos, como aos que assistem, pois é algo novo que Ihes está sendo mostrado, e este fato causa, no primeiro instante, uma perturbação positiva na estrutura cognitiva e após a busca pelo entendimento do novo provoca uma assimilação do que é apresentado ao aluno.

Os alunos do $8^{\circ}$ ano participaram de uma atividade relacionada ao conteúdo, que é explanado durante todo 0 ano: 0 corpo humano. A turma se dividiu em duplas, as quais ficam responsáveis por adquirir uma camiseta branca. E, na medida em que são estudadas as estruturas do corpo humano, construíram representações dos órgãos e anexaram na camiseta, no lugar em 
que correspondem no corpo. Foram representados os sistemas cardiovascular, respiratório e urinário. Essa atividade promove não somente a interação dos alunos entre si e com a professora durante 0 ano todo, como também favorece a aprendizagem dos alunos, pois constroem seus modelos de acordo com suas concepções sobre os conteúdos, escolhendo os materiais que irão utilizar. A aprendizagem ocorre de forma lúdica, pois é visivel o interesse e dedicação dos alunos na construção dos modelos. Ao final da atividade, a camiseta possibilita a observação dos órgãos, nos lugares em que se encontrariam realmente, porém, obviamente, sendo uma representação do interior do corpo humano, como pode ser observado na Figura 3.

Figura 3: A camiseta confeccionada no $8^{\circ}$ ano sobre as estruturas do corpo humano.

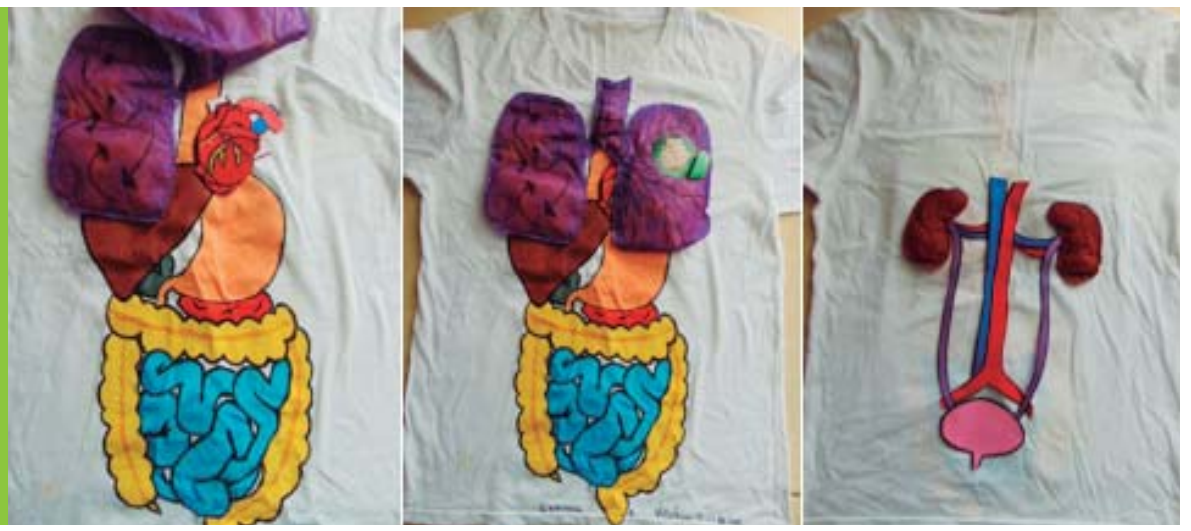

Na turma do $9^{\circ}$ ano é possível notar que não há disponibilidade de um número grande de estratégias. Durante o período em que o estágio foi realizado não houve nenhuma atividade além da aula expositiva e uso do quadro, porém ao longo do ano, segundo relato da professora e também dos alunos, são desenvolvidas algumas ações (poucas, porém não podem ser ignoradas, pois são atividades consideráveis no processo de ensino/aprendizagem). Entre estas, a construção de alguns modelos representacionais, o que pode ser produtivo no âmbito da aprendizagem, pois nesta fase da vida o aluno apresenta uma grande facilidade de abstração e habilidades manuais (CAVICCHIA, 2010). Outra atividade muito interessante é o "jogo da torta na cara", no qual os alunos respondem questões de conteúdos tratados desde $06^{\circ}$ até $09^{\circ}$ ano. É constituído por várias questões e quem não acerta a questão, como imaginado, "leva tortada". É uma atividade que provoca uma interação grande entre os alunos, pois se trata de uma atividade lúdica, porém só constata o que eles já sabem, mesmo tendo um potencial, pequeno, para promover a aprendizagem ou de instigá-los a aprender futuramente, para a participação da mesma atividade. Isto pode acontecer através da metacognição, ou seja, quando instigado, o aluno consegue realizar a ligação da questão com algum conhecimento que não havia compreendido em um estado inicial.

Esta turma, do $9^{\circ}$ ano matutino, é bem característica, diferente de todas as outras observadas em relação ao comportamento. São mais dispersos e com pouca concentração nas aulas, conversam bastante entre si. Não significa que não possuem potencial de aprendizagem, pelo contrário, em alguns (poucos) momentos trazem durante a aula questionamentos muito pertinentes para o ensino de ciências. A professora relatou que esta turma específica não apresenta muito interesse nas práticas, e algumas deixam de ser realizadas por este motivo, sendo oferecidas ao $9^{\circ}$ ano do turno vespertino, porque são mais receptíveis à estas abordagens.

A aprendizagem significativa impõe que o aluno manifeste um "mecanismo (processo) de aprendizagem significativa" e, para Ausubel (2003), existem quatro critérios que indicam 0 momento em que 0 aluno assumiu uma responsabilidade adequada em relação à aprendizagem: 1) quando ele aceita a tarefa de aprender ativamente, tentando entender 0 material que the ensina; 2) ao tentar integrar o conhecimento aos que já possui; 3) quando não evita o esforço por novas aprendizagens, não exigindo que o professor faça tudo por ele; e 4) quando faz perguntas necessárias sobre o que não compreende (LEBOEUF; BATISTA, 2013). Esses mecanismos sugerem que a aprendizagem significativa, além de idiossincrática, é ativa, uma vez que é 0 aluno quem decide em que tipo de processo de aprendizagem irá se envolver: significativa ou mecânica, e qual será o nível de esforço que fará na construção de novos significados. 
As causas de um comportamento não receptivo em relação às abordagens didáticas podem estar relacionadas ao fato de a professora não se identificar com a disciplina de física (conforme seu próprio relato), e/ou com a turma, ou quanto ao comportamento deles estarem relacionados às mudanças hormonais, visto que a adolescência é um período de transição para a fase adulta e de mudanças físicas e psicológicas. Além disso, informações indicam que desde $06^{\circ}$ ano já demonstravam indícios deste comportamento.

Com relação a estas avaliações, ficam no campo hipotético, pois há a necessidade de uma análise mais aprofundada acerca dos fatores que tornam esta turma do matutino, com estas características ímpares e não favoráveis ao processo de ensino/aprendizagem, porém deve ser realizada em um período maior de observação.

Retomando 0 estudo das didáticas utilizadas, é relevante afirmar que, além destas práticas distintas nas etapas de ensino, as ferramentas auxiliares em comum entre todos os níveis são: vídeos curtos com associação do conteúdo ao cotidiano dos alunos; como todas as salas de aula possuem televisão com internet, também é um recurso bem utilizado pela professora; e ainda são realizadas atividades descritivas individual e em grupos. Quase todas as estratégias utilizadas possuem direcionamento para a avaliação.

Moreira ressalta que: "A facilitação da aprendizagem significativa depende mais de uma nova postura docente, de uma nova diretriz escolar, do que de novas metodologias, até mesmo as mais modernas tecnologias de informação e comunicação" (MOREIRA, 2010, p. 23).

Essa facilitação seráainda mais efetiva se incorporar "sobretudo de novas maneiras de avaliar", uma vez que no cenário atual da educação o contexto é muito mais behaviorista do que construtivista e de certa forma este ainda determina as práticas docentes. A sociedade em geral exige "provas" do que 0 aluno "sabe ou não sabe", e este tipo de avaliação comportamentalista promove a aprendizagem mecânica, uma vez que não entra no âmbito da compreensão (MOREIRA, 2010).

Neste aspecto, é relevante indicar que as diversas formas de avaliar alcançam um número maior de sujeitos, uma vez que nem todos aprendem da mesma forma e com as mesmas ferramentas didáticas.

\section{Conclusões}

Com a análise de todas as estratégias analisadas, pode-se afirmar que as aulas se caracterizam de forma geral como dialogadas, com a utilização de diversos instrumentos, baseados em teorias construtivistas e com pouco uso do quadro, o contrário de uma didática que muitas vezes se torna maçante para os alunos. Essa pedagogia pode ser comparada a uma pedagogia relacional, na qual professor e aluno participam e constroem o conhecimento. Da forma como a professora apresenta os conteúdos, torna-se mais fácil manter a atenção dos alunos, instiga ao diálogo e eles têm a possibilidade de expor suas concepções. Essa variedade de instrumentos pedagógicos favorece, dentre outras coisas, a exploração das diferentes características de aprendizagem de cada indivíduo. Ela acentua os conhecimentos gerados e também permite a tomada de decisão; dá significado a conceitos de difícil compreensão; exige a participação ativa; motiva; desperta a criatividade, a participação e o prazer de aprender, ou seja, favorece em muitos aspectos a cognição.

Outra característica a ser mencionada é que há uma abordagem construtivista da professora quando ela questiona sobre os conhecimentos prévios, porém não há elaboração de hipóteses. Assim sendo, talvez o único complemento que possa ser sugerido nas abordagens seria de, além de constatar os conhecimentos prévios dos alunos, atentar à construção de hipóteses que possam ser testadas ao longo dos procedimentos.

Desta forma, o aluno pode ter consciência do que realmente aprendeu, em comparação ao que ele sabia em um estado inicial ou o contrário. Assim, permite a auto avaliação e a constatação, se houve ou não aprendizagem. Nesse caso, o professor se torna um mediador que atua entre 0 aluno e 0 conhecimento.

As respostas são cedidas a todas as dúvidas apresentadas. Esta prática, por um lado se torna cansativa ao professor, sempre tendo que narrar e expor o conteúdo de forma completa. Além disso, o professor tem seus conhecimentos testados, mas os dos alunos é que deveriam ser testados. 
Há também mais fatores que interferem no processo de ensino e aprendizagem, como as relações sociais e afetivas estabelecidas entre professor e aluno, e essa relação é conturbada com relação à turma do $9^{\circ}$ ano. Com relação a isto, a única proposta a ser indicada seria a reflexão sobre os objetivos que se tem sobre estes alunos e repensar as estratégias que possam ter afinidade com os mesmos, podendo ser que se tornem necessárias abordagens didáticas diferentes das que são oferecidas ao $9^{\circ}$ ano do período vespertino, pois há a concepção de que os sujeitos aprendem de forma diferente.

Entende-se, então, que as estratégias didáticas utilizadas, podem se constituir facilitadoras no processo de ensino/aprendizagem, porém não se pode afirmar que estas por si só são determinantes neste processo. Deve-se lembrar que há diversas variáveis que interferem neste sistema e que dependem tanto dos alunos como dos professores. Isto foi bem evidente, refletindo a respeito do $9^{\circ}$ ano do período matutino, em relação às demais turmas. Dentre esses fatores mencionados, destaca-se a motivação de ambas as partes, pois a partir das aspirações de cada um é que serão atingidos os objetivos.

As dificuldades para a execução deste estudo foram mínimas, uma vez que a instituição escolar e a professora foram extremamente receptivos e se colocaram na posição de auxiliar em qualquer dificuldade na observação. Com relação ao que foi observado, de forma geral, pode-se expor uma dificuldade encontrada neste caso e por muitos professores construtivistas, que é a falta de estrutura nas escolas, como de laboratório, ou um simples espaço para exposição dos trabalhos construídos em sala.

Conclui-se que para que a aprendizagem seja significativa a atividade docente deve ser planejada, refletida, avaliada e diversificada, valorizando a diversidade e respeitando os ritmos de aprendizagem dos alunos.

\section{Referências}

AUSUBEL, D. P. Aquisição e Retenção do Conhecimento: Uma perspectiva cognitiva. Lisboa: Plátano, 2003.

BRASIL. Lei no 9.394, de 20 de dezembro de 1996. Estabelece as diretrizes e bases da educação nacional. MEC, 1996. Disponível em: < http://portal.mec.gov.br/seesp/arquivos/ pdf/lei9394_Idbn1.pdf>, acesso em: 15 de mar. 2016.

Parâmetros Curriculares Nacionais: Ciências Naturais. Secretaria de Educação Fundamental. Brasília: MEC, 1997.

CAVICCHIA, D. C. 0 desenvolvimento da criança nos primeiros anos de vida. In.: Universidade Estadual Paulista. Caderno de Formação: Formação de professores educação infantil princípios e fundamentos, v. 1. São Paulo: Cultura Acadêmica Editora, 2010. p. 13-27.

FRISON et al. Livro didático como instrumento de apoio para construção de propostas de ensino de ciências naturais. In: VII Enpec - Encontro Nacional de Pesquisas em Ciências. Florianópolis, 2009.

Gil, A. C. Métodos e técnicas de pesquisa. 6. ed. São Paulo: Atlas, 2008.

HAIDT, R. C. C. Curso de didática geral. 6. ed. São Paulo: Ática, 1999.

LEBOEUF, H. A.; BATISTA, I. L. Uso do "v" de Gowin na formação docente em ciências para os anos iniciais do ensino fundamental. Revista Investigações em Ensino de Ciências, v. 18, n. 3, p. 697-721, 2013.

MOREIRA, M. A. Teorias de Aprendizagem. São Paulo: EPU, 1999.

0 que é afinal Aprendizagem Significativa? Revista Qurriculum, La Laguna, n. 25, p. 29-56, 2012.

Aprendizagem significativa crítica. Disponível em: < http://www.if.ufrgs. br/ moreira/apsigcritport.pdf>, acesso em: 17 mai. 2016.

VYGOTSKY, L. S. A Formação Social da Mente. 4. ed. São Paulo: Martins Fontes Editora LTDA, 1991. 